\title{
11
}

\section{The Journey of Higher Degree Apprenticeships}

\section{Claire Hughes and Gillian Saieva}

\section{Introduction}

Real world learning (RWL) is becoming a vital component for curriculum enhancement, due to the realisation that "real-world rigour is required to increase the adaptability of higher education graduates in a fast-changing business environment" (Woodside, 2018, p. 2). This chapter will explore how RWL pedagogies are at the centre of the Higher and Degree Apprenticeships (HDAs) outlining the history and rationale for the introduction of HDAs and the benefits for all stakeholders undertaking HDAs. The added value that RWL brings to HDAs highlights the career and personal gains that this pedagogy brings to both apprentice and organisations alike. In addition, discussion and case studies will

Case studies: Lisa Rowe, University in the North of England, Claire Hughes and Gillian Saieva

C. Hughes $(\bowtie) \bullet$ G. Saieva

Solent University, Southampton, UK

e-mail: claire.hughes@solent.ac.uk 
identify the journey map for the design, development and implementation of this type of pedagogy, along with discussion around the challenges.

To set the scene, it should be remembered that the very essence of building and developing higher-level skills was a vital component of HDAs, which neatly dovetails into RWL pedagogies. To quality assure the HDAs, each apprenticeship had a set standard, developed across the trailblazer group, made up of training providers, employers and professional bodies. In addition, the Quality Assurance Agency introduced apprenticeship characteristics:

Apprenticeships incorporating higher education are constituted as first and foremost a job which requires work-integrated learning ... the workplace becomes a site for the development and generation of knowledge, understanding, skills and professional behaviours rather than just a site for their application. (QAA, 2019)

The definition means that there is a direction and set of requirements for curriculum design, which gives a direction to training providers to enable adherence and illustration of learning gain for each individual and organisation. However, these requirements do underline the need for innovation into the curriculum design, delivery and partnership working with the employer to ensure all these requirements were met.

It is acknowledged that this chapter does not seek to provide a fullrange solution, but a reflection on the lessons learnt so far and seeks to cover some of the main areas for consideration. To assist this a concept map was developed to frame the insights for this chapter and can be seen in full in Fig. 11.1.

\section{What Are Higher Degree Apprenticeships?}

The government's role to ensure the UK is not caught in a 'low skills equilibrium' has long held a view that vocational training and apprenticeship policies are key to moving production up the value-added chain, enhancing productivity and economic growth across a wider range of sectors (Wilson et al., 2003). 


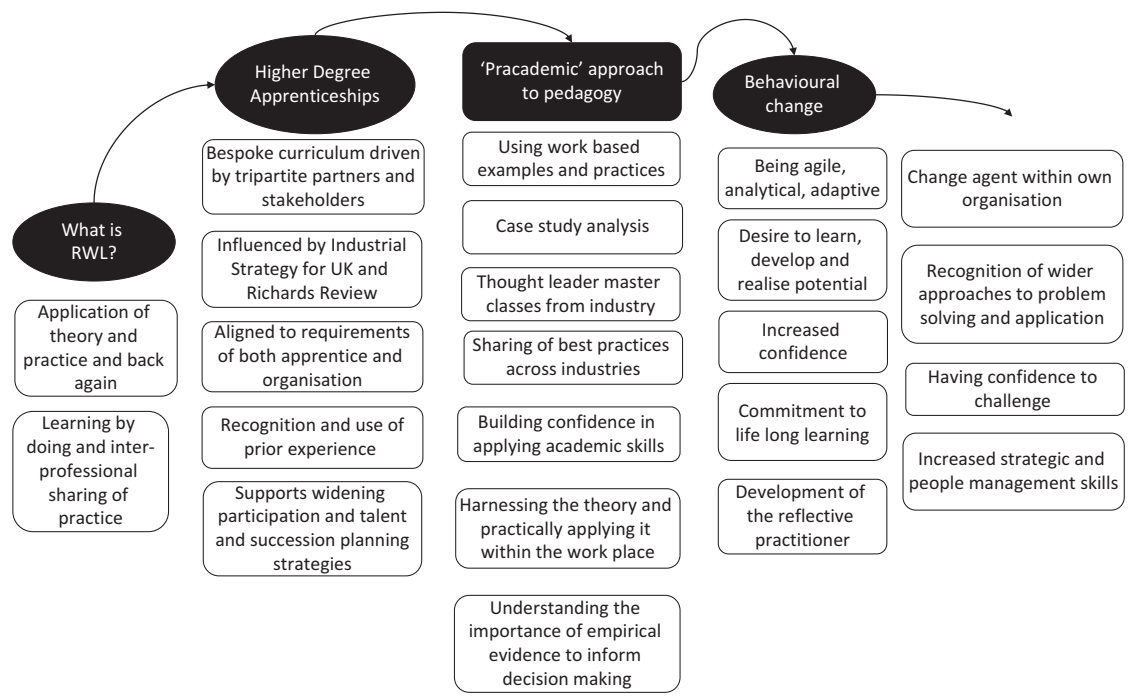

Fig. 11.1 Concept map from the authors

Higher level and degree apprenticeships have brought together different cultures and methods of designing, delivering and assessing knowledge, skills and behaviours, funding learners and learning providers, data reporting, quality management and its review or inspection. (Felce, 2019)

HDAs are a recent addition to the learning and development circuit of apprenticeships, and while this chapter seeks to give an understanding of their reason for being, it is important to know their origins. Apprenticeships in England have had a long history, from the first national apprenticeship system of training in 1563 with the medieval craft guilds, to the professions and newer industries of engineering, shipbuilding, plumbing and electrical work during the 1900s (House of Commons Library: MirzaDavies, 2015). The last three decades have seen the highest rate of reform with schemes such as 'Modern Apprentices' announced in 1993, 'Advanced Apprenticeships' in 2004 and after the general election of 2010, 'Higher Apprenticeships' followed (House of Commons Library: Mirza-Davies, 2015). This was further shaped by new minimum standards introduced in 2012, developed by Trailblazer groups, consisting of employers, professional bodies and training providers to develop 
apprenticeship standards against professions. In 2017 the apprenticeship levy was introduced, where organisations with an annual salary bill of more than $£ 3$ million incurred a levy payable at $0.5 \%$ directly into a subHMRC account; this could then be claimed back by organisations for drawdown of the monies to training providers as payment for apprenticeships (ESFA, 2019). This also allowed non-levy payers to be supported against these unclaimed funds with incentives to pay only $5 \%$ of the training cost, with the balance drawn from the unspent pot of money held by the government. The policy drivers for the introduction of the apprenticeship levy are still considered by many to fund young people into employment; however, as argued by Anderson (2019), productivity is the overarching reason. This change further saw the development of HDAs in 2016 and the university sector entering the apprenticeships market. Higher apprenticeships can span from level 4 to level 7, while Degree apprenticeships are at level 6-7 to include bachelors and masters degree programmes.

This was a significant new policy direction for the UK, and much of this recent change was a result of the government in 2012 launching the Richard Review of Apprenticeships to answer questions about their future direction and understand further their purpose for employers, individuals and their impact on the economy (HM Government, 2012). They were interested in the quality of the current provision and what 'good' might look like at a time when the focus was towards economic recovery, with an anticipation of growth; this presented key questions around how best to invest towards a knowledge economy, changing demands against technology, scientific knowledge and career changes, particularly at the latter stages of individuals' careers and multi-age workforces. It was also anticipated that a call for investment in new and higher-level skills would put an increased premium on knowledge work as a direct result of the sustained rise of international markets such as China and India who were competing in the upstream part of the value chain and contributing to the innovation landscape (Lund et al., 2019). Predications around this shift towards knowledge-intensive activities, with a focus on cognitive and non-cognitive skills, identified that a re-balancing of skills needed to take place, where people needed to be able to innovate, learn and develop against a broader range of skills (Joynes et al., 2019). There has been a 
renewed focus for apprenticeships to deliver on design, commercial and communications skills and not solely technical skills as previously, leading to the need for a real world approach to learning and teaching.

The Richard Review (HM Government, 2012) received much scrutiny; however, its alignment to the government's approach at the time of launch evoked the below statement from the then Business SecretaryVince Cable (2012):

The Richard Review echoes the Government's current thinking on putting employers in the driving seat of our apprenticeship programme. This will be vital to ensure the skills of our workforce fit with employer needs ... His recommendations will help us to build on the current successes of our apprenticeships programme and tailor a programme which is sustainable, high-quality and meets the changing needs of our economy in the decades to come.

The essence of upskilling the UK was also evidenced in the Industrial Strategy which blueprinted the vision of Theresa May's Conservative Government, launched in 2016 after the EU Referendum, which aligned to industries of the future and sought to set out to improve the lives of people and the pathway to productivity for the UK (HM Government, 2017). With a focus on the 'Grand Challenges' this aligned to the changing needs of the economy with a firm vision to put the UK at the forefront of tackling major global changes which will transform the future, such as artificial intelligence, the ageing society, clean growth and future of mobility (HM Government, 2017). With these challenges in mind, HDAs sought to deliver against key areas of knowledge and skills development, to support both young and existing employees retain highly skilled jobs in an ever-changing global economy through both theoretical and RWL pedagogic practices.

RWL is at the core of the HDAs, along with social mobility and widening participation, as it allows study towards a qualification not always initially accessible to a greater range of apprentices. It could be suggested that this new-found confidence is because it is based around work and that financial constraints of study are relieved as the employer is the sponsor (Parrett, 2018). There has been much discussion across this area as to 
who and what level should be accessing the funding to be able to apply for an HDA (UVAC, 2019); however, it could be argued that by the very nature of the ethos and underpinning rationale for introducing the HDAs, these should remain open to all, especially as the UK Industrial Strategy clearly outlines that upskilling and filling in skills gaps is still an imperative focus:

Higher education plays a significant role in bringing benefits for the UK economy, particularly in the provision of higher-level skills that are needed by employers both nationally and within local areas. (HM Government, 2017)

HDAs may also enable organisations to attract and retain potentially untapped talent and perhaps reduce the growing trend of employers struggling to fill posts (CIPD, 2019); which will be ever important in these current complex economic, political and social landscapes.

In addition to the 'upskilling' that is observed, there are also a range of benefits for social change too. Many employers have embraced HDAs as an opportunity to reflect diversity and widening participation. An example of the potential impact is evident in the work between the police service in Nottinghamshire with the University of Derby, where they have claimed HDAs have resulted in a 20\% increase in female recruits, a $9 \%$ increase in recruitment from Black, Asian and minority ethnic (BAME) groups and overall $50 \%$ of recruits being the first in their family to enter Higher Education (UUK, 2019). The case study below highlights further the success that HDAs are having in driving change and opportunity, including social mobility, gender equality and closing the skills gap in leadership.

\section{Case Study 1}

HDAs are drivers for social change and opportunity (Lisa Rowe, Director of Business Engagement and Partnerships, University of Chester Business School, UK) 
The Centre for Work Related Studies (CWRS) at University of Chester launched the Chartered Manager Degree Apprenticeship (CMDA) in Autumn 2016, followed by the Senior Leaders Master's Degree Apprenticeship (SLMDA) in Spring 2018. The CMDA comprises a BA (Hons) Business Management and Leadership, operating with 6 cohorts and 91 apprentices. The SLMDA facilitates two pathways - the MA/ MSc Business and Management for Senior Leaders or the Master of Business Administration, currently comprising 8 cohorts and 164 apprentices. Data to inform this case study has been collected from a sample of these apprentices, their employers and academic tutors as part of a doctoral thesis. The research took place through unstructured and semistructured interviews and questionnaires and was followed by systematic analysis to identify themes and patterns in the data. The profile of apprentices is diverse and indicates a distinct shift at undergraduate in terms of both gender and age, complementing both the full-time provision and CWRS's traditional suite of work-based learning programmes (Table 11.1). The data also suggest that management degree apprenticeships may be an effective intervention to improve gender equality in senior roles, with a significant majority of female management apprentices.

As Wilton (2018) points out, $47 \%$ of UK Chartered Manager Degree Apprentices are from some of the UK's most economically deprived regions; therefore, the benefits of increased social mobility are becoming apparent. Yet, the latent effects of social-economic status in formative years is also an important consideration, evidenced by stories of low income and limited parental aspirations as early barriers to HE: "We were

Table 11.1 Profile of degree and master's level apprentices at University of Chester

\begin{tabular}{llllll}
\hline Programme & Enrolments & Male & Female & $\begin{array}{l}\text { Average } \\
\text { age }\end{array}$ & $\begin{array}{l}\text { Consultancy } \\
\text { projects }\end{array}$ \\
\hline CMDA & 91 & 21 & $70(77 \%)$ & 32 & 273 \\
SLMDA & 164 & $\begin{array}{c}(23 \%) \\
(33 \%)\end{array}$ & $\begin{array}{c}110 \\
(67 \%)\end{array}$ & 40 & 164 \\
Combined & 255 & 75 & 180 & 36 & 437 \\
\hline
\end{tabular}


all (six siblings) made to work from when we were thirteen so we didn't have those opportunities" (Business Impact Manager, NHS). The majority of CMDA respondents have previously been unable to access $\mathrm{HE}$ because of their background, whereas SLMDA respondents have been restricted by their individual financial and family responsibilities, illustrated by the comment: "I have two children under the age of three and both my wife and I work full time, so we don't receive supported childcare yet. Coupled with the fact I am still paying off my undergraduate debt meant I couldn't justify the costs of an MA or MBA" (Facilities Manager, NHS).

As such, HLAs provide an overwhelming opportunity for mid-career advancement at work. Educational aspirations and goal setting for career progression are widely evident, but whilst mature apprentices might appear to have significant workplace experience at programme entry, it is apparent that this does not necessarily translate to the vital high-level leadership and management skills, behaviours and competencies, valued as essential components of career development by both employers and employees. Data from a number of employer interviews confirm the difficulty in recruiting individuals equipped with these skills, specifically 'capable', 'motivated', 'person-centred leaders' who can 'influence', 'problem-solve' and 'create impact'.

Here, there is increasing evidence that both programmes can develop critical leadership skills to meet industry demand:

Having a masters will provide the level of qualifications expected for this type of role. This course has given me insight into a broad range of tools and techniques that have helped me develop my leadership style, but also give me skills in financial management, research and managing organisational change, which are key aspects to the roles I will be looking to in the future. (HR Manager, Manufacturing)

This endorsement of leadership development through work-based learning is further evidenced by the growing numbers of apprentices who have already received significant promotions whilst on-programme, in itself providing motivation to other apprentices within the organisation and cohort: "Being an NHS Manager with a clinical background, I 
realised I would benefit from completing a management course to gain business knowledge and skills. I have been able to quickly apply many of the theories I have learnt to my job role. During a tender presentation to commissioners I used critical success factors to demonstrate our unique selling points in comparison to private provider competitors. In addition, I have utilised the Marketing module in preparation for writing the Trust bid to continue to deliver the service. These are just a couple of many examples of how I have put what I have learnt into practice to gain promotion" (Director, NHS).

There is also extensive evidence of enhanced engagement and workplace performance from undertaking these courses; "He's just stepped up to the mark, he's grown overnight" (Team Supervisor, Manufacturing); "I've not seen that that motivation in her and I think this coursework has given her the stamina to be able to do that" (Team Leader, PR \& Marketing Agency); "In terms of achievements in this last 6 to 8 months she's probably already advanced beyond what some people achieve in most of their careers" (Office Administrator, Engineering Sector).

Indeed, the success of the two programmes has brought numerous other tangible benefits. The department's close links with employers enable the academic team to maintain their own practitioner knowledge and more effectively support individuals, organisations and the wider local economy with critical skills development needs. The current cohorts alone will deliver more than 400 individually negotiated consultancy projects, creating a wealth of research and knowledge transfer opportunities, significant leadership skills development outcomes and unprecedented talent sourcing and retention for the region.

\section{The Benefits for the Apprentice, Employer and Training Providers of Higher Degree Apprenticeships}

Having reviewed the macro benefits of apprenticeships, the next section seeks to explain in greater detail the perceived benefits across all three parties: apprentice, employer and training provider. The essence of the 
tripartite relationship would be key to the success of this approach with all parties responsible for the outcome.

Key to the apprenticeship approach is the employer being at the heart of the process. Unlike traditional education learning, HDAs are driven by employer demand in the first instance; therefore, the issue around employability and designing courses to fit with what industry demands is part of the development process. The formerly known Institute for Apprenticeships was created in 2016, now known as The Institute for Apprenticeships and Technical Education (IfATE), to oversee the development, approval and publication of apprenticeship standards and assessment plans and latterly the occupational maps for $\mathrm{T}$ levels and apprenticeships. They work with the Trailblazer groups and have a further External Quality Assurance role and are accountable for the quality of apprenticeships. The Department of Education (DfE) hold accountability for the England Apprenticeship Programme, while the Education and Skills Funding Agency (ESFA) is responsible for policy and funding of apprenticeships and ensuring effective delivery of programmes across training providers. All training providers must be on the Register of Approved Training Providers (RoATP) in order to be able to engage with apprenticeships.

The Future of Degree Apprenticeships Report (Universities UK, 2019) provides a summary of the overarching key benefits that HDAs deliver across the three parties:

- Apprentices are positive about the opportunities that degree apprenticeships provide for gaining a degree, and often a professional qualification as well, while they are learning and earning in the workplace.

- Employers are positive about the contribution apprentices make to their organisations and the opportunity it gives to address key skills shortages, enhance opportunities for their own employees and widen the talent pool of their recruits.

- Universities are positive about the stronger relationships they have been able to build with employers, the enhanced opportunities for success and progression they can provide for their apprentices, and the innovation they have promoted in learning and teaching. 
In order to deliver against the 'knowledge-led economy' (HM Government, 2017) and support higher economic growth with higherlevel skills development, HDAs provide the opportunity for universities and education providers to get closer to employers to support talent development within organisations by upskilling existing and new staff and further address talent shortages, particularly in public services, which incorporates RWL.

To firstly consider the perceived benefits for the apprentice, students of any age can now consider a funded route to higher education and skills development. The dilemma for the school leaver to go to university with the assumed debt, or to try and find a job, has the additional option to be employed directly with an organisation that has engaged with the upskilling benefits of using the apprenticeship route for talent development. This provides the apprentice with both job security and career prospects, alongside the benefits of RWL in learning on the job, focused mentoring from their line manager and experiencing higher education and professional pedagogy, such as reflective practice to support life-long learning. The 'earn while you learn' caption is of key attraction to both the potential apprentice and parents. However, research suggests a 'second-class' stigma is still held towards apprenticeships and HDAs, when compared with conventional university degrees, with the ongoing perception that HDAs require fewer academic skills (Universities UK, 2019).

While more needs to be done to showcase the impact and quality of apprenticeships to date, the process to gain an HDA contains additional rigour over and above a traditional degree, and in non-integrated apprenticeship degree cases, to include an end point assessment (EPA), carried out by an external organisation (EPAO). This assesses the apprentice's knowledge, skills and behaviours against the apprenticeship standard and requires reflection against key skills, knowledge and behaviour learning areas. This often includes a work-based learning project and viva. The apprentice emerges from the process having evidenced a wide range of RWL attributes and subsequently is more employable moving forwards due to the nature of the applied real world learning that has taken place throughout their programme of learning as an apprentice. These upskilling' benefits are then observed not just by the individual but within the organisation too. 


\section{The Synergies Between HDAs and RWL Pedagogy}

For any HDA there is a requirement to prove that learning gain has taken place over and above skills that the apprentice had already, prior to starting; funding relies on this (ESFA, 2019). Initially, it can be difficult to understand how this may happen, given the large number of experienced senior managers undertaking HDAs, as opposed to the 16-21-year-old grouping who normally start from a lower-level skill base, where returns may be more easily observed. To overcome this a skills mapping and analysis system can be introduced, which illustrates that learning gain is actually very tangible and impactful, as highlighted by the feedback from experienced professional apprentices: "I now have knowledge and a pool of resources to draw down upon and fills that previous skills gaps" and "I like that the course gives extra value in the networking opportunities and identifying how organisations approach different challenges."

Given that the apprentices are required by the apprenticeship standard to not only learn the academic knowledge, but to evidence use of it within the workplace, they quickly become reflective practitioners to identify how this has developed their skills across their job roles; this gives RWL the perfect platform. Therefore, it could be suggested that the very essence of HDAs marrying the workplace and academia, making it practically academic, is why the RWL pedagogy is a natural mode of delivering the provision.

\section{Challenges for Curriculum Design, Delivery and Partnership Working}

Whilst the HDAs new starters are still missing the high targets that the government set, there are still a large number of apprentices starting programmes, with more having been at the mature and post-graduate level than perhaps was initially anticipated (Moules, 2019). With most training providers working with multiple partners, across both open and 
closed cohorts, design can be complex in order to meet the requirements of illustrating learning gain across the different aims of multiple partners, all of which have different development objectives. Therefore, it is important to cover all the design bases and work in partnership together on this (QAA, 2019). The very first steps should be to design and develop the course against the standard with a careful match to ensure that both the theory and RWL can be incorporated into each unit. Once this mapping and curriculum design has taken place flexibility also needs to be developed, to meet the wide range of individual and organisational experience, to ensure they build the core topic knowledge, whilst then being able to apply this to their own job role and institutions. This can be achieved from the outset in the tripartite relationship building where understanding of what development needs to take place from an individual point of view can then lead to holistic enhancement of the wider team and organisational development too. This was evidenced in the feedback received from apprentices: "It is also helping the wider team as she is able to use her knowledge and bring in practices that perhaps weren't done, and by sharing this across the team it widens the knowledge", and "He came back and explained what he had done and is now implementing this approach to the Board of Directors for our latest project."

The curricula can be designed to cover as many bases as possible at the design and development stages, without having prior knowledge of the specific requirements and then further developed after discussion across the tripartite partnership. Universities may also be in the position of co-designing a course with a specific employer, which brings both benefits in that the curriculum can be tailored specifically to their combined needs, but can also lead to challenges too. Case study 2 gives an example of how the curriculum can have a bespoke design when solely working with one large employer. This also outlines the benefits of the sole partnership, allowing for experts to co-deliver some of the knowledge input with a strong real world learning output. However, whilst this reduces some challenges, the case study also outlines some of the observed difficulties of working with a single organisation and reflects on advice for peers on how to proceed on a similar journey, including cross stakeholder working. 


\section{Case Study 2}

The single partner challenges (University based in the North of the UK)

The year 2017 was the start of our Chartered Manager Degree Apprenticeship (CMDA) journey. A feasibility study was followed by submission of a successful business case and finally acceptance of the programme by the University Programme Approval Group. The year 2018 saw us with a viable programme offering and seeking students.

Conversations with a local public sector organisation led to our engaging with and being successful in a tendering process. We had secured a large employer with a significant local presence who believed they would be sending at least 60 students per year over the next 5 years to our CMDA programme. This exceeded our initial expectations, and focus shifted away from engaging with new employers.

Working with one employer has obvious advantages. Discussions around contracts were more straightforward and the admissions process (significantly different to typical university admissions) was facilitated by receiving documentation through just one channel. Managing the tripartite meetings was also significantly easier, with colleagues able to condense student/mentor appointments into one day cutting down on administration and travel time.

When it came to planning and delivering the teaching, tutors were able to design sessions specific to the particular workplace, a real advantage for such a practical course. Indeed, the organisation provided guest speakers who were able to contextualise some of the learning for the accounting and Human Resource Managment (HRM) modules. Student feedback on this was extremely positive. They commented, both informally and through tutorials, how they felt they were able to apply the learning to the workplace almost from the start. Indeed, to meet the CMDA standards it was important that students were able to see how the knowledge could be applied in the workplace. The knowledge delivery in the classroom was supported by discussions around how this could support the development of the learner and the success of the organisation. Assessments required students to take this new knowledge into the 
workplace, reflecting on how effectively management thinking could be applied in the real world.

However, despite the advantages of working with one large employer, care needs to be taken. It soon became apparent that the numbers of students joining the course would be significantly lower than projected. The number was lower again for the next cohort a year later. Whilst we were assured this was in no way related to the quality of the programme, this was little consolation. Teaching staff had been recruited in anticipation of the projected students, and the actual numbers had very real implications for the sustainability of the programme. The phrase all our eggs in one basket' was all too apt.

Whilst the confirmation of the contract was tremendous news, the employer requested a course start date 6 weeks hence. The programme had been designed; however, the short lead in time presented us with resourcing issues. Keen to establish a good rapport with the employer, we agreed a start date in 10 weeks, a real challenge.

The administrative procedures proved to be a major hurdle to clear. Highly experienced, our admissions team were used to processing courses with traditional $2 \times 11$-week semesters. Assessment deadlines, re-sit periods and exam boards were all scheduled and resourced in line with the established academic year. The CMDA proved to be something of a 'culture shock' and required some sensitive negotiations between two organisations with long-established procedures. However, there was again an advantage to having only one employer. Planning meetings included administrative staff from both sides, something which may not have been practical with a dozen smaller employers. This helped to develop a positive working relationship from the outset.

The employer invited us to showcase our offering at a number of inhouse apprenticeship recruitment events. These were to encourage applications for both the Level 6 CMDA and the Level 3 and Level 5 programmes which were being delivered by the employer. Interest was strong, but the majority of prospective applicants were in roles more suited to levels 3 and 5, depleting the potential Level 6 numbers.

As numbers for the second CMDA intake were again lower than hoped, the employer agreed that the next cohort could be opened up to allow applications from other sectors and employers. Maintaining a course with just one employer had become unsustainable. 
Lessons learned:

In such a competitive environment, securing a contract with a large employer is a real bonus. However, these are some of the lessons we have taken away from our experience:

1. Clarify the numbers: It is worthwhile establishing how the employer has arrived at their projections, and the impact of factors such as alternative training provision which may divert potential students. This may seem like common sense, however, when there is only one employer this is so very important.

2. Keep an eye on the market: Whilst the programme numbers are increasing with more employers joining, the concerns could have been addressed sooner if conversations and plans had been made earlier.

3. Level of understanding of the qualification/process: Do not assume that the employer has a full understanding of how things work. Misunderstandings/misconceptions can have quite significant impacts.

4. Student understanding and awareness of the commitment: Get involved in the recruitment and internal induction processes. It is possible that the students are unaware of what is involved, having quickly jumped at the chance of a free course/CPD with limited information.

5. Staff involvement: There were real advantages gained by including support staff in conversations with the employer. This helped to gain internal support for this new programme as well as speeding up the planning process.

Putting RWL holistically at the core of an HDA curriculum enables a strong pedagogic approach, but it needs more than just pedagogic drivers to ensure success. It is vital to create strong tripartite relationships and solutions between all parties: training provider, employer and apprentice as all have significant roles to play to ensure success (UVAC, 2016).

The employer and apprentice are the key players in really identifying where these learning gains are required to create the most developmental impact. This also enables identification of the most appropriate HDA that will bring the most learning gain. At the application stage, a skills scan of the apprentice's current and future skills can be reviewed with other application documents, such as a personal reflective statement, to 
outline the apprentice's commitment and fit to professional development with their long-term individual and organisational strategic objectives.

The training provider then starts the development of the apprentice and work-based mentor in building knowledge of the HDA standard and evidence collection. This can take place in many forms, but an initial indepth interview can be useful here. The starting point for this can be discussing the skills scan and then objective setting for outputs that the individual and organisation are ideally requiring. In this way the individual and organisational drivers are incorporated even at this initial stage leading the way for a work-based development plan for the learning gain, set in the ethos of RWL, to be identified even before starting the HDA. This is still based on generic course learning outcomes but by working in this tripartite partnership, bespoke design can be incorporated. In addition, this also acts as a valuable relationship builder between the tripartite parties and aids an early understanding for the training provider of any extra support or specific organisational learning outcomes that the employer ideally requires. These specific requirements can then be mapped and supported, for example, case studies, mentor matching, network building, guest speakers and workshops.

It has been outlined that developing the correct curriculum, working closely in the tripartite relationship and ensuring an RWL learning and teaching experience are key elements to drive success, yet another element of pastoral support is vital too. Case study 3 outlines the experiences to date around delivering apprenticeship provision to groups of apprentices who are working whilst studying. Support needs to be embedded to ensure that both the academic and work-based learning outcomes can be achieved, whilst maintaining the apprentices' well-being.

\section{Case Study 3}

Understanding the apprentices' health and well-being challenges within the learning experience across the Solent University CMDA, SLMDA and Operations and Departmental Manager apprenticeship programmes (Claire Hughes, Apprenticeship Programme Manager and Course Leader Business and Gillian Saieva, Head of Subject, Business, Finance and Accountancy, Solent University, UK) 
Undertaking an HDA, whilst working a significant job position, alongside other personal commitments, can be challenging for students. Added to this, apprentices are normally experienced and successful in their job roles, so are used to being experts within their knowledge and/or comfort zones, yet find themselves entering into an HDA, which can push them outside of those zones. The HDA is academically demanding, given they may have limited experience of higher education, whilst having to continue working significant jobs and managing other personal commitments, this can stretch apprentices' well-being and lead to severe doubts of confidence about whether they should or can study at this level. This is not a new phenomenon (Norman \& Hyland, 2003) and is still prevalent. The most confident of person may need to be brought back on track, and this brings many challenges both for pedagogic and pastoral practices. To ensure that the apprentice is supported a number of innovations can be applied, which includes having a personal professional development unit as a core part of the curriculum, which supports their own personal journey in self-awareness, their drivers, managing teams, their leadership styles and their future goals. Giving apprentices time to reflect in this way is a luxury not often taken within the traditional work-based setting. It heightens self-awareness and encourages openness and is assisted by the tripartite relationship that is designed to support this development. This also enables permission for apprentices to openly discuss their strengths and identify a plan for their future personal and career development. This self-awareness improves working and personal professional development practices in the workplace alongside increasing confidence and resilience.

The feedback from both apprentices and employers below illustrates the power that correctly designed support can bring. When asked about how the HDA had benefitted them, apprentices fed back 'life-changing' and 'changed them as a manager, for the better'. The same question for employers brought up the themes that the apprentices had more confidence and positive changes were observed within their behaviours and the apprentice's scope to see the 'bigger strategic' picture. Assigning a mentor can also be beneficial especially when an apprentice is having 
doubts or struggling to juggle all their commitments and can be a powerful tripartite relationship builder as exemplified below:

a massive thank you to you for all your help support and guidance. You have boosted my confidence when needed and was much appreciated.

Thank you for all your support and encouragement, it would not have been possible to complete and achieve my qualification without this.

Assisted by an established tripartite relationship, it is important to keep the employer aware of students' challenges and become the intermediary when necessary. This is valued by all parties, especially when a difficult conversation is needed about the apprentice's well-being or lack of achievements, alongside the inevitable conversations about the $20 \%$ offthe-job training elements where issues from either side are reported.

In addition to other support, the apprenticeship progress reviews are vital. By going out to the workplace to build relationships with employers and apprentices, this allows complex or difficult situations to be solution driven and is a powerful way to remind all parties just how much RWL in work and learning can be achieved. All of this combined, works to build up not only confidence of the apprentice and manager in their apprentice, but the confidence to learn and take this knowledge back into the workplace and apply it for the benefit of the teams and organisation: "it's professionalised the work that I do" and "it is that they are getting credited for doing their jobs professionally and from a cultural prospective I think it is showing that there is a buy in to staff development and career progression...it's a long-term investment."

It should be impressed upon both the apprentice and organisation that studying for an HDA is not the easiest route to take due to all the challenges outlined above; it does mean that apprentices have to draw on their resilience and time management skills. Therefore, it is vital to ensure that strong pastoral processes are in place to ensure the apprentices' wellbeing and to convey any concerns with the organisation, as this is part of the tripartite relationship role and responsibilities. 


\section{The Challenges for External Organisations in Supporting Real World Learning for HDAs}

When creating an RWL learning pedagogy there is the need for the internal organisational infrastructure to be carefully constructed. This comes with the discussions about the onboarding and during the induction processes; both the apprentice and the employer need to be clear about the requirements as the apprentice needs to be able to work within the scope of the standard and draw the evidence down from their own working practices. For example, the finance role in many organisations is often devolved from individual job roles; this has created challenges in collecting this evidence base and solutions having to be identified between the tri-partite parties.

These are the areas that when undertaking the skills scan need to be agreed at an early stage, with regular review points, so as to avoid setting an apprentice up to fail. Work-based mentors and line managers need to be just as supported in what the standard requires, as it is imperative the line manager buys-into and gives full support. Without either of these it would limit the positive RWL impact across the whole team and would be detrimental to the learning gain of the apprentice and potentially lead to failure to meet the End Point Assessment requirements for the apprenticeship.

A further infrastructure challenge that has been observed is how the employer approaches the minimum of $20 \%$ off the job training element. All parties normally understand the need to give this time and sign learning agreements which outline how this will be delivered upon. In some cases, organisations don't pro-actively acknowledge or plan for the apprentice's need to be able to delegate some responsibilities, to allow for the $20 \%$ time. This can lead to the apprentice's well-being challenged by having $20 \%$ less time to do the 'day job'. Some organisations may face challenges in the resource re-allocation that is required and the messaging here is vital from the outset. Although short-term operational issues may ensue, the apprentice's learning gain has the potential to being in an excellent return in both the short and longer term. Many employers have fed back that they were able to delegate their own work to their 
apprentice team member due to their expanding knowledge and confidence, which then left them more time for the top-line strategy work:

[talking about benefits of knowledge built up]...to support my manager, I have taken some of the higher-level work load from her and taking it and running with it and just being more confident to get on with it.

\section{The Challenges of Implementation of HDAs Within Higher Education}

In higher education non-standard courses have faced difficulties aligning to the infrastructures of traditional course management (JISC, 2013) when, for example, IT systems are not aligned to a non-standard format, assessment regulations need amendments and courses do not fit the traditional year for academic exam boards. There is a need for more flexibility in how higher education is taught to increase access (Higher Education Commission, 2017), especially as HDAs will continue to grow in popularity and these 'non-standard' courses increasingly become 'the norm'. It is important to recognise these challenges and to have processes in place through careful planning and work groups made up from the full range of stakeholders to align these practices. Best practices have seen crossuniversity working groups set up, with all the key academic and professional service stakeholders meeting regularly to identify and resolve working practices challenges to create a streamlined and uniformed approach to the internal management of the HDAs, along with partnership contract meetings where challenges and best practice are discussed.

\section{Conclusion}

Those working in the area of higher degree apprenticeships already know how life changing these courses can be for apprentices, not only in their working and leaderships practices, or in their outputs that benefit their teams and organisations, but to their personal development and increase in confidence too. HDAs reflect the essence of real world learning that 
develops students for employability and learning, and, in this instance, is done very explicitly through the immediate course and pedagogy itself.

The HDAs provide a valuable contribution to management and leadership skills across UK organisations, which could contribute to the UK productivity issues "management skills could account for a quarter of the productivity gap between the UK and the US" (HM Government, 2017). Given those challenges, it is vital that RWL stays as the core narrative of the HDAs as without, the individual and organisational learning gains would just be a download of topic knowledge, defeating the very reason that the HDAs were introduced.

The journey when developing, implementing and delivering HDAs can at times be a hard and winding one, but as with every long journey, the satisfaction at the end of completing it depletes the painful parts of the journey. HDAs are at the cutting edge of changing practice in higher education, and by using careful mapping, sharing best practice, crossuniversity working and learning to work in tripartite partnerships, the learning journey for all parties can be successful. HDA complexity within traditional higher education supports the need for more research to better understand how to make an excellent apprenticeship experience for all.

\section{References}

Anderson, A., 2019. Keynote: Exploring the Future Challenges and Priorities of Higher and Degree Apprenticeships Provision, UVAC Higher Apprenticeships Conference

Commons Library: UK Parliament: Mirza-Davies, J. (2015). A short history of apprenticeships in England: From medieval craft guilds to the twenty-first century. Retrieved from https://commonslibrary.parliament.uk/economybusiness/work-incomes/a-short-history-of-apprenticeships-in-england-frommedieval-craft-guilds-to-the-twenty-first-century/

CIPD 2019 Labour Market outlook view from employers Autun. (2019). Accessed 4 January 2020. Available: https://www.cipd.co.uk/Images/labourmarket-outlook-autumn-2019_tcm18-67336.pdf

Education and Skills Funding Agency. (2019). Apprenticeship funding rules for main providers. Retrieved from https://assets.publishing.service.gov.uk/gov- 
ernment/uploads/system/uploads/attachment_data/file/821581/1920_ Provider_Rules_Version_1.0_FINAL.pdf

Felce, A. (2019). Managing the quality of higher education in apprenticeships. Higher Education, Skills and Work-Based Learning. 9.10.1108/ HESWBL-10-2018-0106.

Higher Education Commission. (2017). One size won't fit all. Retrieved from https://www.policyconnect.org.uk/sites/site_pc/files/report/1005/fieldreportdownload/hec-web.pdf

HM Government. (2012). The Richard review of apprenticeships. Retrieved from https:/www.gov.uk/government/news/the-richard-review-of-apprenticeships HM Government. (2017). Industrial strategy building a Britain fit for the future. Retrieved from https://assets.publishing.service.gov.uk/government/uploads/ system/uploads/attachment_data/file/730048/industrial-strategy-whitepaper-web-ready-a4-version.pdf

Joynes, C., Rossignoli, S., \& Fenyiwa Amonoo-Kuofi, E. (2019). 21st Century Skills: Evidence of issues in definition, demand and delivery for development contexts (K4D Helpdesk Report). Brighton, UK: Institute of Development Studies.

JISC. (2013). Non standard courses. Retrieved from https://www.jisc.ac.uk/ guides/managing-course-information/non-standard-courses

Lund, S., Manyika, J., Woetzel, J., Bughin, J., Krishnan, M., Seong, J., \& Muir, M. (2019). Globalisation in transition: The future of trade and value chains. McKinsey Global Institute. Retrieved from https:// www.mckinsey.com/featured-insights/innovation-and-growth/ globalization-in-transition-the-future-of-trade-and-value-chains

Moules, J. (2019). Apprenticeship numbers rise in England for the first time since levy reforms. Retrieved from https://www.ft.com/content/ a3000176-5144-11e9-b401-8d9ef1626294

Norman, M., \& Hyland, T. (2003) The role of confidence in lifelong learning. Retrieved from http://sprite.bolton.ac.uk/201/1/ed_journals-7.pdf

Parrett, S. (2018). A degree of confusion over apprenticeships. TES. Retrieved from https://www.tes.com/news/degree-confusion-over-apprenticeships

Quality Assurance Agency. (2019). Higher education in apprenticeships characteristics Statement A. Retrieved from https://www.qaa.ac.uk/news-events/ news/supporting-higher-education-in-apprenticeships-qaa-publishesnew-guidance 
Universities UK. (2019). The future of degree apprenticeships \#Earnandlearn. Retrieved from https:/www.universitiesuk.ac.uk/policy-and-analysis/ reports/Documents/2019/future-degree-apprenticeships.pdf

University Vocational Awards Council. (2016). The future growth of degree apprenticeships. Retrieved from https://www.universitiesuk.ac.uk/policyand-analysis/reports/downloads/FutureGrowthDegreeApprenticeships.pdf

UVAC. (2019). Review of Post-18 education and funding June 2019. Retrieved from https://uvac.ac.uk/augar-and-apprenticeships-uvacs-initial-response/

Wilson, R., Hogarth, T., Bosworth, D., Dickerson, A., Green, A., Jacobs, C., ... Watson, S. (2003). Tackling the low skills equilibrium: A review of issues and some new evidence, A report for the DTI. Coventry: IER, University of Warwick. Wilton, P. (2018, April 26). Management degree apprenticeships: The UK's engine room where overalls are not required. Universities UK. Retrieved from https:// www.universitiesuk.ac.uk/blog/Pages/management-degree-apprenticeshipsUK-engine-room.aspx

Woodside, J. (2018, July 9). Real-world rigour: An integrative learning approach for industry and higher education. Sage Journal. https://doi. org/10.1177/0950422218784535

Open Access This chapter is licensed under the terms of the Creative Commons Attribution 4.0 International License (http://creativecommons.org/licenses/ by/4.0/), which permits use, sharing, adaptation, distribution and reproduction in any medium or format, as long as you give appropriate credit to the original author(s) and the source, provide a link to the Creative Commons licence and indicate if changes were made.

The images or other third party material in this chapter are included in the chapter's Creative Commons licence, unless indicated otherwise in a credit line to the material. If material is not included in the chapter's Creative Commons licence and your intended use is not permitted by statutory regulation or exceeds the permitted use, you will need to obtain permission directly from the copyright holder.

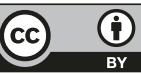

